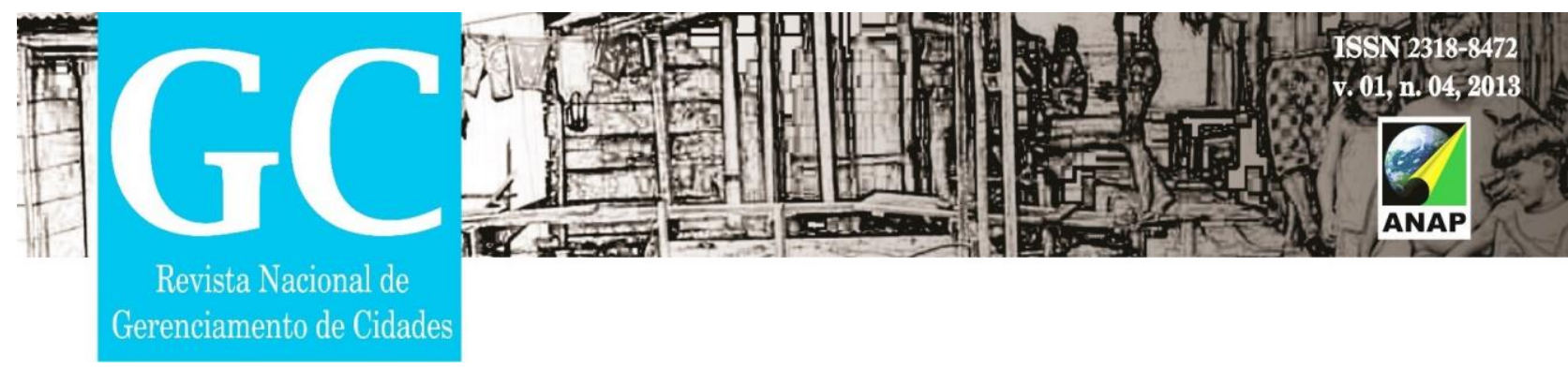

Titulo do Trabalho

\title{
TELHADOS VERDES E SUA CONTRIBUIÇÃO PARA A SUSTENTABILIDADE DAS CIDADES.
}

Nome da Autora Principal

Marcinéia Vaz Moraes de Oliveira

Nome da Orientadora

Jeane Aparecida Rombi de Godoy Rosin

Instituição ou Empresa

FACCAT - Faculdade de Ciências Contábeis e Administração de Tupã - Tupã/ SP.

E-mail de contato

marcineia.au@gmail.com

Palavras-chave

Telhados Verdes. Permeabilidade. Biodiversidade.

\section{INTRODUÇÃO}

Os telhados verdes se referem ao uso da vegetação sobre a laje ou sobre planos da cobertura, e podem ser empregados em diversos tipos de edificações, consequentemente proporcionando formas e efeitos diversificados.

Há registros do uso de telhados verdes em construções desde os anos 600 a.C. na Mesopotâmia e Babilônia. Conforme mostra a história, no Império Romano, o uso de árvores nas coberturas dos edifícios era comum. (BEATRICE, 2011, p. 28).

Entre os séculos XVI e XVII, o uso de telhados verdes se espalhou por diversos países em todo o mundo. 


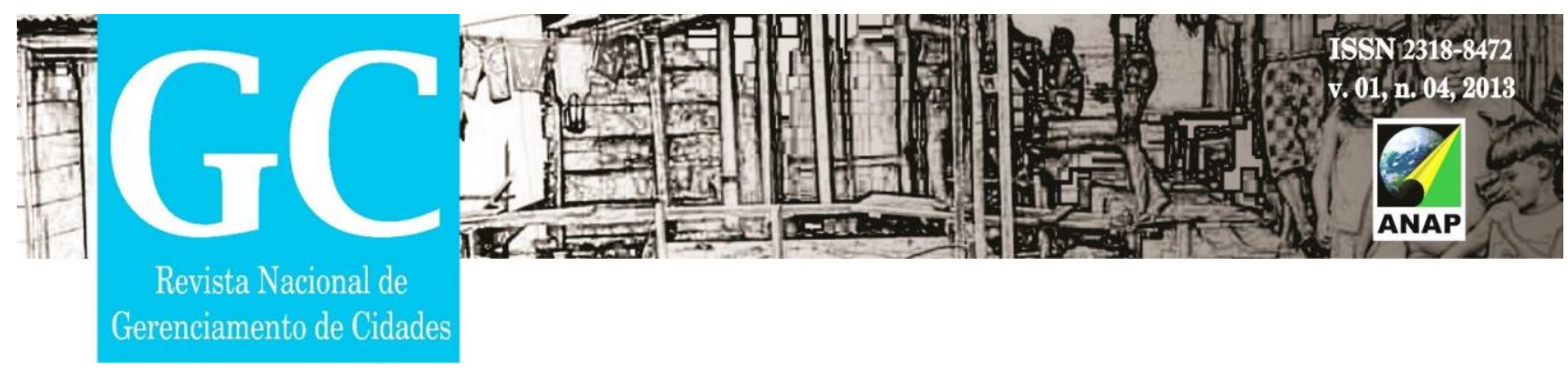

Desde os anos 60 a Alemanha, com uma consciência ecológica, vem desenvolvendo técnicas construtivas de telhados verdes, com o intuito de amenizar os impactos ambientais causados pela urbanização e mais recentemente, o governo vem estabelecendo guias e normas, como descreve Beatrice (2011, p. 32):

$\mathrm{Na}$ Alemanha, como meio de estabelecer o sucesso de implantação da tecnologia de telhados verdes, foram estabelecidos planos, guias e normas, como o Guideline for the Planning, Execution and Upkeep of Green Roof, iniciado pelo governo e conduzido pela organização "The Landscap Research, Development and Construction Society (FLL), publicado em 1990 e revisado em 1995 e 2002, no qual indicam e orientam os métodos, materiais e técnicas, adequadas para o planejamento, instalação, execução e manutenção de telhados verdes.

"Hoje, diversos países da Europa adotaram as coberturas verdes devido aos seus benefícios, assim como Estados Unidos e Canadá. Existem vários programas municipais e leis federais de incentivo à incorporação de coberturas verdes nas novas edificações, além de organizações não-governamentais especializadas em divulgar e aplicar as coberturas verdes." (FERRAZ, 2012, p.11).

No Brasil, o uso de coberturas verdes se iniciou na década de 90, e estão mais presentes nos estados de Santa Catarina e Rio Grande do Sul, onde já existem leis referentes aos telhados verdes (FERRAZ, 2012).

As coberturas verdes podem ser uma das alternativas para melhorar a gestão das águas pluviais urbanas, devido à sua capacidade de aumento da área permeável nas cidades, as quais se apresentam como um dos principais desafios para a gestão urbana, conforme enfatiza Baldessar (2012, p.17),

A gestão de águas pluviais tornou-se uma questão de urgência para muitos centros urbanos. Cada vez mais, a cidade é coberta por superfícies impermeáveis: ruas e edificações, que não retêm a precipitação e, assim, produzem mais e mais volume no escoamento de água.

A finalidade do uso dos telhados verdes não se limita apenas à questão de benefícios ao clima e ao aumento da área permeável urbana, mas também às questões de bem estar da população em geral, pois o verde melhora a estética dos cinzentos 


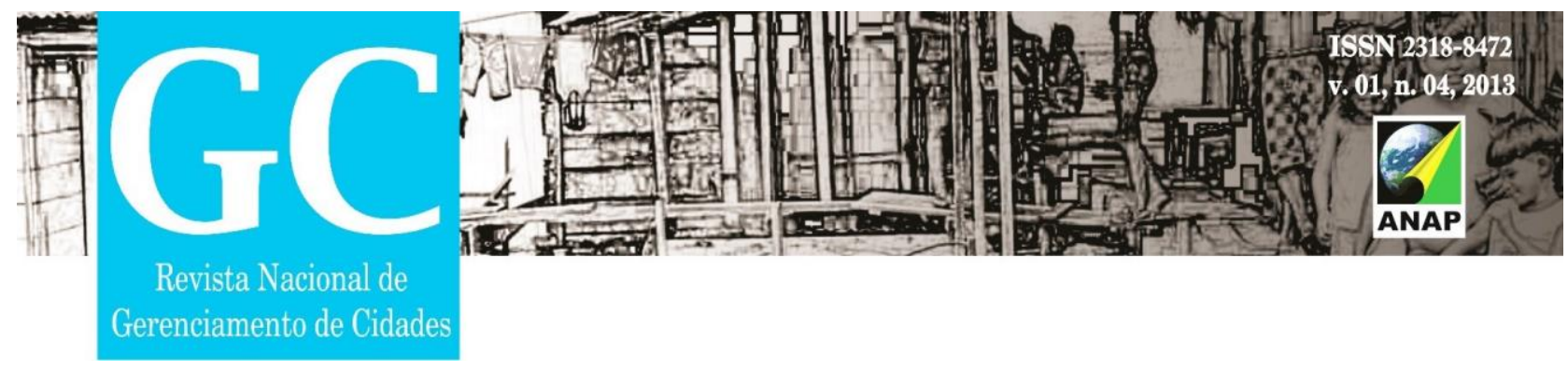

centros urbanos, como um dos motivos importantes citados abaixo pela Associação Internacional de Telhados Verdes,

Para a IGRA (Internacional Green Roof Association), existem dois motivos principais para a utilização do telhado verde, um é a visão agradável de um maravilhoso telhado jardim, o outro, um hábitat para a fauna e a flora nos cinzentos centros urbanos. (CATUZZO, 2013, p. 61).

Outra importância atribuída ao uso dos telhados verdes urbanos é citada pela Federação Europeia das Associações de Telhados Verdes - EFB, ao tratar de estudos desenvolvidos na Suíça e em Londres, onde os resultados obtidos mostraram que os telhados verdes devem ser projetados dentre suas diversas funções, para atender objetivos específicos de conservação da biodiversidade local.

\section{OBJETIVO GERAL}

- Apontar os benefícios que o telhado verde pode proporcionar ao meio urbano e ao meio ambiente.

\section{OBJETIVOS ESPECÍFICOS}

- Destacar a importância do telhado verde com aumento da área permeável;

- Ressaltar a importância do aumento da biodiversidade da flora nas cidades através dos telhados verdes.

- Propor a construção de telhados verdes utilizando plantas nativas;

\section{METODOLOGIA}

Utilizou se de levantamentos bibliográficos de pesquisas realizadas sobre telhados verdes: artigos, monografias, dissertações e teses, além de outros trabalhos que se relacionam com a temática e que são importantes por apresentar pesquisas e estudos de caso que mostram a eficiência e os benefícios que as coberturas verdes podem trazer ao 


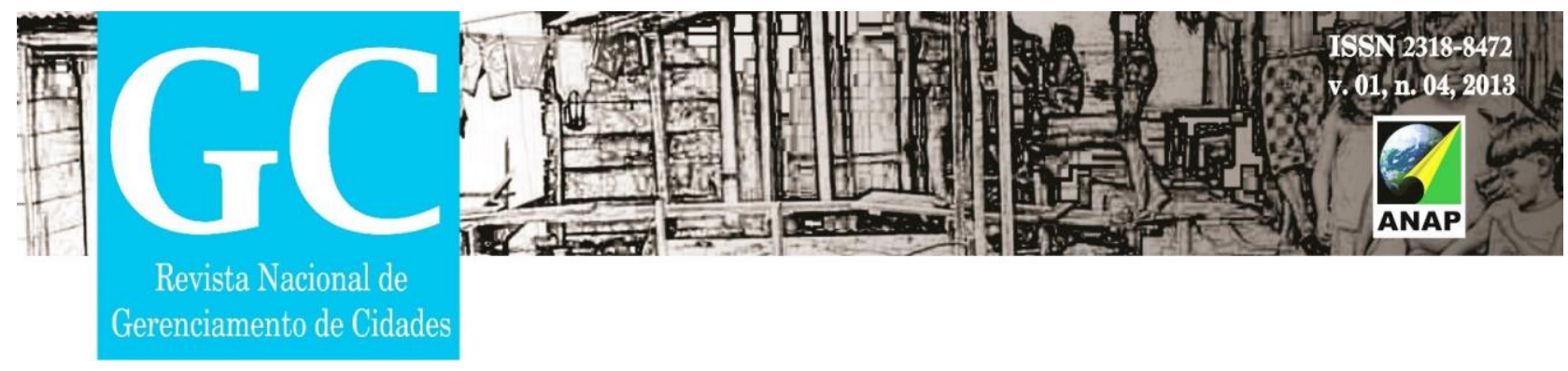

meio urbano, meio ambiente e à qualidade de vida das comunidades nas mais diversas localidades.

\section{RESULTADO(S)}

O crescimento populacional e a ocupação desordenada dos espaços urbanos, promove invariavelmente, o aumento da impermeabilização das superfícies, reduzindo a capacidade infiltração e absorção, além de intensificar o escoamento superficial, o que tem provocado danos de diversas ordens.

Para Ribeiro (2010, p. 38), "A implantação da Infraestrutura verde nos espaços propicia consideráveis ganhos de saúde ambiental, sejam eles físicos, sociais, econômicos ou estéticos", neste sentido" são inegáveis os ganhos climáticos e ambientais quando se adotam soluções verdes nas cidades", os quais deveriam ser incorporados em novas concepções da engenharia urbana.

No que se refere ao aumento da permeabilidade, como sendo um dos benefícios que os telhados verdes trazem ao meio urbano, pode-se citar (SILVA, 2007), ao defender que, os telhados verdes podem servir para aumentar a permeabilidade do solo, reduzindo o escoamento superficial e minimizando os impactos decorrentes das inundações. Complementando este enfoque, (FERREIRA, 2007), ressalta que os telhados verdes retêm parte da água, funcionando como pequenas encostas que liberam a água mais lentamente, evitando o colapso na drenagem urbana e aumentando a umidade nos dias posteriores à ocorrência de eventos pluviométricos.

Um outro fator que confere importância ao uso dos telhados verdes é o reaproveitamento da água da chuva, conforme (BALDESSAR, 2012),

\footnotetext{
A água da chuva sobre telhados pode ser recolhida em cisternas. Nos telhados verdes a água da chuva é filtrada pela vegetação e pelo substrato, reduzindo os agentes poluidores encontrados no ar poluído e que são incorporados à água da chuva durante sua precipitação.
}

Em seus estudos, Minke, (2005, apud Ferreira 2007, p. 3), procurou mostrar a capacidade de retenção de água por um telhado verde, em porcentagem " [...] somente 


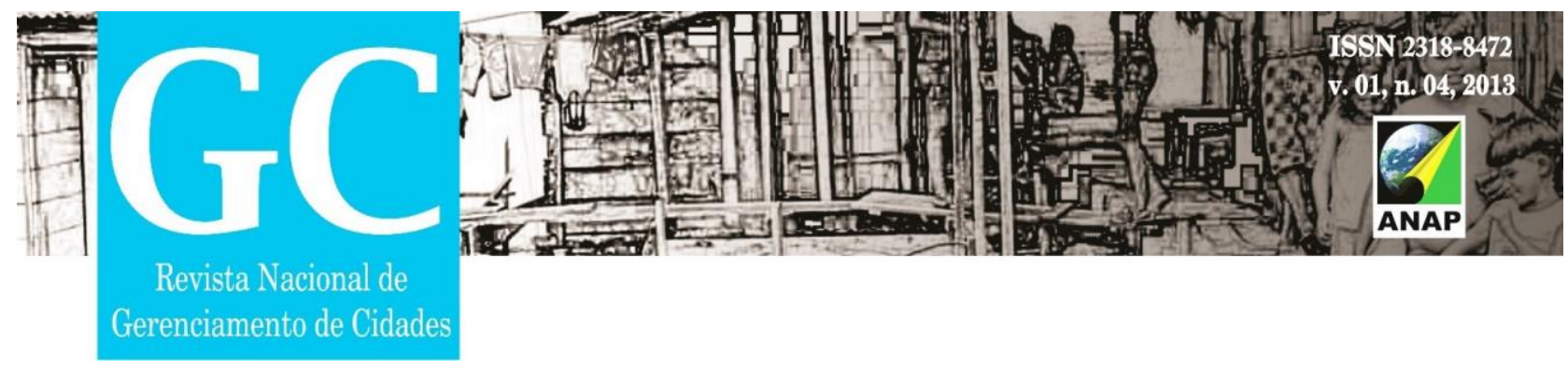

$30 \%$ da chuva que cai, deságua e $70 \%$ é retida pelos tetos verdes e/ou são evaporadas, índice que pode sofrer alterações devido a inclinação do teto."

Além dos benefícios de captação de água da chuva, isolamento térmico, purificação do ar, entre outros, o telhado verde pode auxiliar na manutenção de um maior número de espécies de plantas nativas dentro da área urbana, conforme afirma Duarte, 2012, citando YEANG 2011,

Os telhados verdes podem vir a exercer importantes funções à biodiversidade nativa, principalmente por fornecerem um habitat diferenciado e relativamente isolado de fatores de estresse para a planta que se aloca no terreno urbano, como a competição com espécies exóticas altamente invasoras, como o capim Braquiária (Brachiaria sp) e o capim gordura (Melinis minutiflora) e a proteção contra predação antrópica e de outros animais.

Sabe-se que quanto maior a diversidade de espécies nativas, mais resiliente se torna o meio ambiente, portanto, faz-se necessário citar (DUARTE, 2012), onde o referido autor, afirma que a composição de espécies nativas e diversificadas para a construção dos telhados verdes, faz com que a biodiversidade urbana torne-se mais resistente às espécies invasoras e aos impactos ambientais.

\section{CONCLUSÕES}

O levantamento bibliográfico evidenciou a necessidade de mais estudos referentes à implantação de telhados verdes com plantas nativas brasileiras.

Os autores não deixam de se referir à importância da utilização de plantas diversificadas e nativas na composição dos telhados verdes, mas ficou evidente a necessidade de elaboração de pesquisas referentes ao uso de plantas nativas brasileiras na composição dos telhados verdes.

O Brasil é um país de grande extensão territorial e consequentemente possui climas e biomas variados ao longo de seu território e é necessário estudos sobre tipologias de cobertura que se adaptem ao clima e plantas que podem sobreviver nas coberturas e que são nativas do local específico de implantação do telhado verde. 


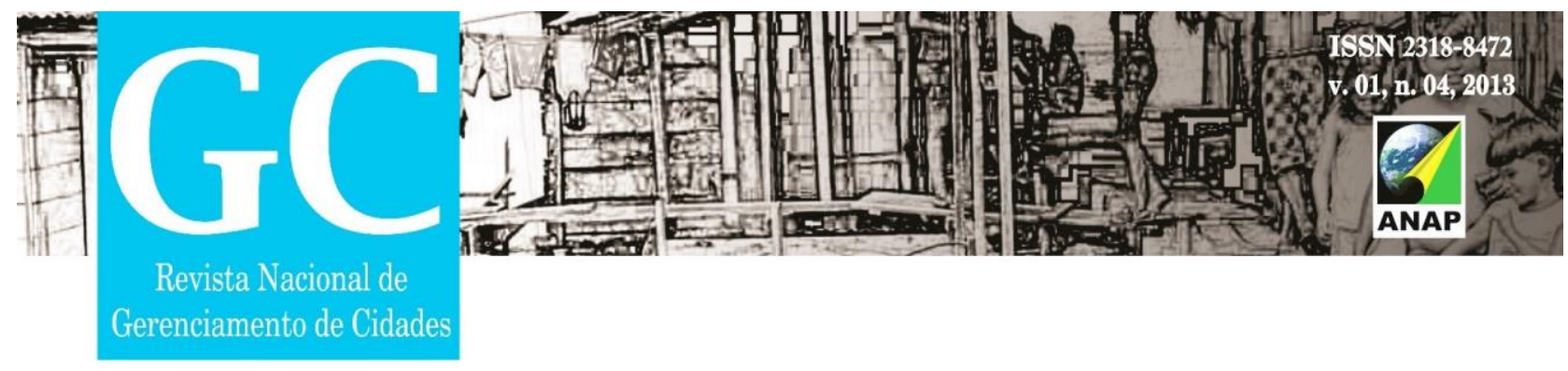

A composição das espécies vegetais nos telhados verdes, devem proporcionar uma estética agradável à habitação e ao meio urbano, assim como trazer benefícios de redução de temperatura, permeabilidade, reaproveitamento da água, mas também benefícios que possam não ser sentidos em curto prazo, mas que se ignorados podem ser catastróficos ao meio ambiente, como o uso inadequado de plantas nativas associadas a espécies variadas, que podem não se adaptarem na composição das coberturas verdes. Em face do exposto, torna-se fundamental, a busca de novas pesquisas, de novos estudos que tenham como propósito a busca de conhecimento referente a aplicabilidade de espécies nativas na infraestrutura verde, especificamente em estruturas de, onde os benefícios resultantes poderiam ser significativamente inúmeros.

\section{REFERÊNCIAS}

BALDESSAR, S. M. N. Telhado verde e sua contribuição na redução da vazão da água pluvial escoada. Curitiba, PR. 2012. Dissertação. (Mestrado em Construção Civil) Área de concentração: Ambiente Construído. UFPR, Curitiba. Disponível em: $<$ http://www.prppg.ufpr.br/ppgcc/sites/www.prppg.ufpr.br.ppgcc/files/dissertacoes/d0168.p df $>$ Acesso em 05 jan. 2014.

BEATRICE, C. C. Avaliação do potencial de uso de três espécies vegetais como cobertura leve de telhados em edificações. São Carlos, SP. 2011. Dissertação. (Mestrado em Engenharia Ambiental) - USP, São Carlos. Disponível em: <http://www.teses.usp.br/teses/disponiveis/18/18139/tde-22092011-151752/pt-br.php> Acesso em 05 jan. 2014.

CATUZZO, H. Telhado Verde: impacto positivo na temperatura e umidade do ar. 0 caso da Cidade de São Paulo. São Paulo, 2013. Tese (Doutorado) - Área de Concentração: Geografia Física. Faculdade de Filosofia, Letras e Ciências Humanas da Universidade de São Paulo. Disponível em: <http://www.teses.usp.br/teses/disponiveis/8/8135/tde-18122013-123812/pt-br.php> Acesso em 05 jan. 2014.

DUARTE, D; GAUDERETO, G. L; MATAR, M. R. Aplicação da tecnologia de telhados verdes como meio de preservação e restauração da biodiversidade paulistana. Trabalho final da disciplina: Arquitetura, Ambiente e Desenvolvimento Sustentável. USP. Disponível em: <http://www.usp.br/fau/cursos/graduacao/arq_urbanismo/disciplinas/aut0221/Trabalhos_Fi nais_2012-1/Tetos_Verdes_e_Biodiversidade.pdf> Acesso em 20 out. 2013. 


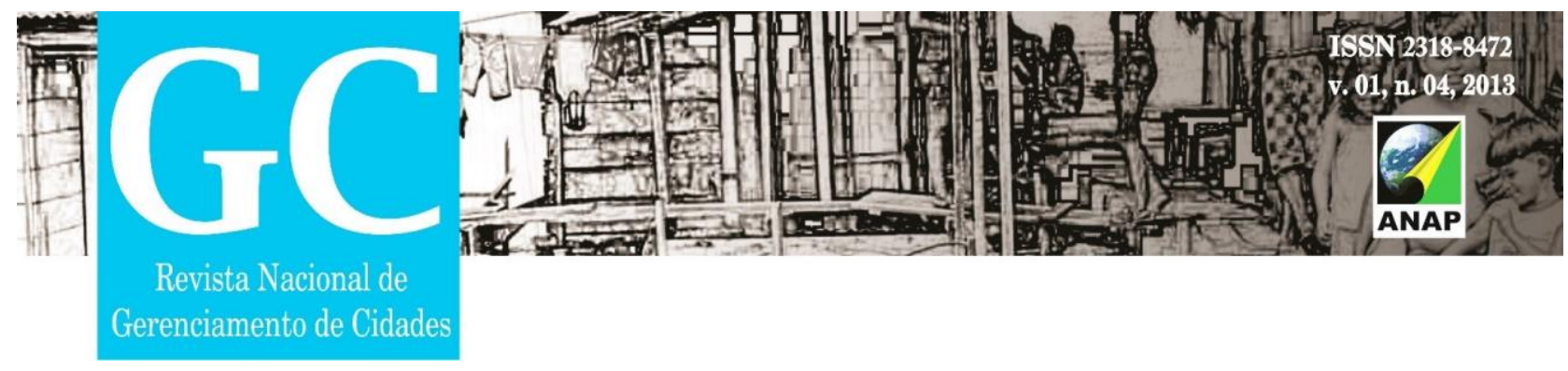

FERRAZ, I. L. O desempenho térmico de um sistema de cobertura verde em comparação ao sistema tradicional de cobertura com telha cerâmica. São Paulo. 2012. Dissertação (Mestrado em Engenharia Civil) - Área de concentração: Engenharia de Construção Civil e Urbana. USP, São Paulo. Disponível em: <http://www.teses.usp.br/teses/disponiveis/3/3146/tde-07062013-144209/pt-br.php Acesso em: 05 dez. 2013.

FERREIRA, M. F. O uso de coberturas vegetais em edificações. Disponível em $<$ http://www.pucrio.br/pibic/relatorio_resumo2007/relatorios/art/art_manoela_de_freitas_fer reira.pdf> Acesso em 15 set. 2013.

RIBEIRO, M. E. J. Infraestrutura Verde: uma estratégia de conexão entre pessoas e lugares. São Paulo, SP. 2010. Tese (Doutorado em Arquitetura e Urbanismo) - Área de concentração: Paisagem e Ambiente. FAUUSP, São Paulo. Disponível em: <http://www.teses.usp.br/teses/disponiveis/16/16135/tde-31052010-150556/pt-br.php> Acesso em 13 nov. 2013.

VERGARA, L.G.L. et al. Experiência de execução de telhado verde: maior integração da edificação à paisagem natural.Recife, PE. 2009. Artigo apresentado no V Encontro Nacional e III Encontro Latino-Americano sobre Edificações e Comunidades Sustentáveis. Disponível em: < http:/www.elecs2013.ufpr.br/wpcontent/uploads/anais/2009/2009_artigo_105.PDF> Acesso em 20 out. 2013.

VANTAGENS Ambientais. Site da Federação Europeia das Associações de Telhados Verdes - $\quad$ EFB. Disponível em: <http://www.efbgreenroof.eu/verband/fachbei/fa01_englisch.html> Acesso em 05 jan. 2014. 